\title{
Stress and Intestinal Flora
}

\author{
Kunio Suzuki, ${ }^{1,2}$ Yoshikatsu Kodama ${ }^{3}$ and Tomotari Mitsuoka ${ }^{1,2,4}$ \\ 1 Animal and Cellular Systems Laboratory, ${ }^{2}$ Frontier Research Program, The Institute of \\ Physical and Chemical Research (RIKEN), Wako, Saitama, 351-01, ${ }^{3}$ Gifu Laboratory, \\ Ghen Corporation, Gifu, Gifu, 501-11, ${ }^{4}$ Department of Biomedical Science, Faculty of \\ Agriculture, The University of Tokyo, Bunkyo-ku, Tokyo, 113
}

(Received for publication, December 28, 1988)

Key words: stress; crowdings; heat; intestinal flora; probiotics

Selye (18) proposed the following hypothesis: an organism activates its ACTHcorticoid defensive reaction between the pituitary and adrenal gland against a variety of stressors. With the above reaction, the organism builds up a resistance to the stress but simultaneously triggers a series of nonspecific processes e.g. hypertrophy of the adrenal gland, degeneration of the thymus and lymphatic system, ulceration of the stomach and duodenum, and reduction in the body weight. These are collectively referred to as the "general adaptation syndrome." "Stressor," defined as any source of stress, includes biological stressors (fatigue, inanition, bacteria, etc.), physical stressors (cold, heat, drafts, radiation, etc.), chemical stressors (chemicals, toxins, etc.), mental and social stressors (tension, anxiety, crowding, noise, etc.), and other stressors. The hormones secreted as a result of stress, however, are not only ACTH-corticoid but also $\beta$-endorphin, $\beta$-lipotropin, prolactin, TSH, thyroxine, glucagon, adrenaline, noradrenaline, and other types. Action by the ACTH-corticoid endocrine system alone is only part of the mechanism of the above "general adaptation syndrome." The current general concept therefore, is that "stress" is a complex physiological reaction caused by multiple hormones secreted under the influence of stressors (Ito (12); Ito and Kawakami (13)). If the above secreted hormones change the physiological condition of the organism; its parasitic and symbiotic intestinal flora should naturally change as well. In turn, changes in the intestinal flora may also reflect the physiological conditions of the organism.

Stress is one of the worst problems affecting the production of livestock such as swine and chickens. It is well known that extremely high or low temperatures, extremely high humidity, overcrowding, and other unfavorable rearing conditions lower the production of the livestock. Antibiotics have generally been added to the feed of livestock to relieve their stress and, in turn, enhance their production. Use of antibiotics with livestock, however, tends to be limited. This is because 
antibiotics remain in the meat of the animal; and because strains resistant to them develop over time. A new method of protecting livestock, which can be replaced with antibiotics, needs to be established. Antibiotics are thought to promote the growth of livestock by inhibiting the growth of harmful intestinal bacteria (Sieburth et al (19); Coates et al (2); Elam et al (7, 8); Forbes and Park (9); Huhtanen and Pensack (11)). The mechanism by which antibiotics carry out this action, however, has yet to be revealed.

In this paper we introduce our study conducted to investigate the effects of crowding and heat stress on the intestinal flora, growth, and feed efficiency of rats and chickens. Part of the aim of the study was also to determine whether administration of the probiotics experimentally prepared from useful bacteria can control the intestinal flora of the animal and relieve its stress.

\section{EFFECT OF CROWDING ON THE INTESTINAL FLORA, GROWTH, AND FEED EFFICIENCY OF RATS}

For the mild-crowding-stress group, twelve 4-week-old SD rats were kept in each of two cages. For the severe-crowding-stress group, twenty-five SD rats were kept in one cage. For the control group, three SD rats were kept in each of four

Table 1. Composition of intestinal flora of rats reared under mild crowding stress

\begin{tabular}{|c|c|c|c|c|}
\hline \multirow{2}{*}{ Bacterial group } & \multicolumn{2}{|c|}{ Control } & \multicolumn{2}{|c|}{ Crowding } \\
\hline & Ileum & Feces & Ileum & Feces \\
\hline Enterobacteriaceae & $6.6 \pm 0.9^{a}(100)^{b}$ & $6.8 \pm 0.9(100)$ & $6.6 \pm 0.6(100)$ & $7.2 \pm 0.1(100)$ \\
\hline Pseudomonas & $(0)$ & $(0)$ & $(17)$ & $2.6 \pm 0.3(50)$ \\
\hline Streptococcus & $7.2 \pm 0.7(100)$ & $8.6 \pm 0.6(100)$ & $7.3 \pm 0.3(100)$ & $8.0 \pm 0.7(100)$ \\
\hline Staphylococcus & $4.3 \pm 1.3(100)$ & $5.7 \pm 1.6(100)$ & $6.8 \pm 0.3^{d}(100)$ & $6.9 \pm 0.4(100)$ \\
\hline Corynebacterium & ( 17$)$ & $(0)$ & $7.0 \pm 0.3^{c}(83)$ & $6.8 \pm 0.5^{d}(100)^{d}$ \\
\hline Bacillus & $(0)$ & $(0)$ & $(0)$ & $-\quad(0)$ \\
\hline Yeast & $(0)$ & $(0)$ & $(0)$ & $(0)$ \\
\hline Mold & $(0)$ & $(0)$ & $(0)$ & $(0)$ \\
\hline Total aerobes & $7.5 \pm 0.6$ & $8.7 \pm 0.6$ & $7.6 \pm 0.2$ & $8.1 \pm 0.5$ \\
\hline Lactobacillus & $9.2 \pm 0.4(100)$ & $9.4 \pm 0.2(100)$ & $9.1 \pm 0.3(100)$ & $9.5 \pm 0.4(100)$ \\
\hline Bifidobacterium & $7.5 \pm 1.9(83)$ & $8.3 \pm 1.3(83)$ & $6.5 \quad(17)$ & $6.6 \quad(17)$ \\
\hline Eubacterium & $7.9 \pm 0.4(83)$ & $8.8 \pm 0.3(100)$ & $7.8 \pm 0.7(67)$ & $8.6 \pm 1.4(83)$ \\
\hline Bacteroides & $6.9 \pm 1.7(100)$ & $9.6 \pm 0.2(100)$ & $7.1 \pm 2.1$ & $9.3 \pm 0.1(100)$ \\
\hline Curved rod & $8.3 \quad(17)$ & $9.3 \pm 0.3(83)$ & $7.6 \quad(17)$ & $9.6 \pm 0.3(100)$ \\
\hline Clostridium & $(0)$ & $9.3 \pm 0.3(100)$ & $(17)$ & $9.5 \pm 0.2(100)$ \\
\hline Fusiform bacteria & ( 17$)$ & $9.2 \pm 0.4(100)$ & $(0)$ & $9.3 \pm 0.4(100)$ \\
\hline Peptococcaceae & $6.7 \pm 1.1(67)$ & $8.8 \pm 0.5(50)$ & $(0)$ & $8.2 \pm 0.7(50)$ \\
\hline Veillonellaceae & $(0)$ & $(0)$ & $(0)$ & $(0)$ \\
\hline Total anaerobes & $9.3 \pm 0.4$ & $10.1 \pm 0.2$ & $9.2 \pm 0.3$ & $10.2 \pm 0.1$ \\
\hline Total bacteria & $9.3 \pm 0.4$ & $10.2 \pm 0.2$ & $9.2 \pm 0.3$ & $10.2 \pm 0.1$ \\
\hline
\end{tabular}


cages. The duration of the experiment was six weeks for the mild-crowding-stress group and four weeks for the severe-crowding-stress group. The temperature and relative humidity were maintained at $25^{\circ} \mathrm{C}$ and $55 \%$, respectively. All animals had access to water and feed ad libitum during the experiment. The body-weight gains and feed efficiencies were measured at regular intervals. At the end of the experiment, six animals were selected at random from each group and the intestinal flora of each animal was examined by the method developed by Mitsuoka et al $(15,16)$.

Table 1 shows the composition of the intestinal flora of the rats reared under mild crowding stress. The results revealed that the number of Staphylococcus and Corynebacterium increased in the ileum and feces while the detection rate of Bifidobacterium was reduced. The mild crowding stress, however, did not affect the bodyweight gains and feed efficiencies of the animals.

Table 2 shows the composition of the intestinal flora of the rats reared under severe crowding stress. The results revealed that the number of Streptococcus, Staphylococcus, Corynebacterium, and total aerobes significantly increased in the ileum and feces. The number of Bacteroides and Peptococcaceae and their detection rates significantly increased in the ileum.

Figure 1 shows that the growth of the severe-crowding-stress group was inhibited even one week after the start of the experiment and, as time passed, the

Table 2. Composition of intestinal flora of rats reared under severe crowding stress

\begin{tabular}{|c|c|c|c|c|c|c|}
\hline \multirow{2}{*}{ Bacterial group } & \multicolumn{4}{|c|}{ Control } & \multicolumn{2}{|c|}{ Crowding } \\
\hline & Ileum & & Feces & & Ileum & Feces \\
\hline Enterobacteriaceae & $7.11 \pm 0.68^{a}$ & $(100)^{b}$ & $7.42 \pm 0.45$ & $(100)$ & $7.42 \pm 0.26(100)$ & $7.26 \pm 0.25(100)$ \\
\hline Pseudomonas & & $(0)$ & & $(0)$ & $(0)$ & $(0)$ \\
\hline Streptococcus & $7.82 \pm 0.65$ & $(100)$ & $8.24 \pm 0.70$ & $(100)$ & $8.76 \pm 0.50^{c}(100)$ & $9.18 \pm 0.31^{c}(100)$ \\
\hline Staphylococcus & $5.01 \pm 0.98$ & $(100)$ & $5.26 \pm 0.42$ & $(100)$ & $6.74 \pm 0.44^{d}(100)$ & $7.86 \pm 0.84^{d}(100)$ \\
\hline Corynebacterium & 8.26 & ( 17$)$ & & $(0)$ & $9.22 \pm 0.81^{d}(100)^{c}$ & $8.93 \pm 0.82^{d}(100)^{d}$ \\
\hline Bacillus & & $(0)$ & & $(0)$ & $(0)$ & $(0)$ \\
\hline Yeast & & $0)$ & & $(0)$ & $(0)$ & $(0)$ \\
\hline Mold & & $(0)$ & & $(0)$ & $(0)$ & $(0)$ \\
\hline Total aerobes & $7.98 \pm 0.68$ & & $8.35 \pm 0.60$ & & $9.47 \pm 0.60^{a}$ & $9.53 \pm 0.37^{d}$ \\
\hline Lactobacillus & $9.05 \pm 0.37$ & $(100)$ & $9.08 \pm 0.41$ & $(100)$ & $9.22 \pm 0.26(100)$ & $9.46 \pm 0.14(100)$ \\
\hline Bifidobacterium & $8.20 \pm 0.44$ & (100) & $8.92 \pm 0.28$ & $(100)$ & $7.89 \pm 0.56(100)$ & $8.63 \pm 0.20(100)$ \\
\hline Eubacterium & $7.76 \pm 0.71$ & ( 33$)$ & $8.67 \pm 0.53$ & ( 83$)$ & $7.98 \pm 0.87(100)$ & $8.23 \pm 0.68(50)$ \\
\hline Bacteroides & $6.09 \pm 2.00$ & ( 83$)$ & $10.15 \pm 0.18$ & $(100)$ & $8.52 \pm 0.63^{d}(100)$ & $10.10 \pm 0.22(100)$ \\
\hline Clostridium & 7.65 & ( 17$)$ & $9.37 \pm 0.35$ & $(100)$ & $(0)$ & $9.39 \pm 0.34(100)$ \\
\hline Curved rod & & $(0)$ & $9.08 \pm 0.52$ & $(100)$ & ( 17$)$ & $9.20 \pm 0.79(100)$ \\
\hline Fusiform bacteria & & $(0)$ & $9.36 \pm 0.33$ & $(100)$ & $(17)$ & $9.70 \pm 0.21(100)$ \\
\hline Spirochaetaceae & & $(0)$ & $8.43 \pm 1.03$ & ( 23) & $(0)$ & $7.97 \pm 0.59(67)$ \\
\hline Peptococcaceae & & $(0)$ & $8.85 \pm 0.85$ & $(100)$ & $8.05 \pm 0.44^{d}(100)^{d}$ & $8.59 \pm 0.74(100)$ \\
\hline Veillonellaceae & & $(0)$ & & $(0)$ & $(0)$ & $(0)$ \\
\hline Total anaerobes & $9.13 \pm 0.39$ & & $10.44 \pm 0.09$ & & $9.46 \pm 0.29$ & $10.48 \pm 0.06$ \\
\hline Total bacteria & $9.18 \pm 0.41$ & & $10.45 \pm 0.08$ & & $9.79 \pm 0.46$ & $10.54 \pm 0.07$ \\
\hline
\end{tabular}




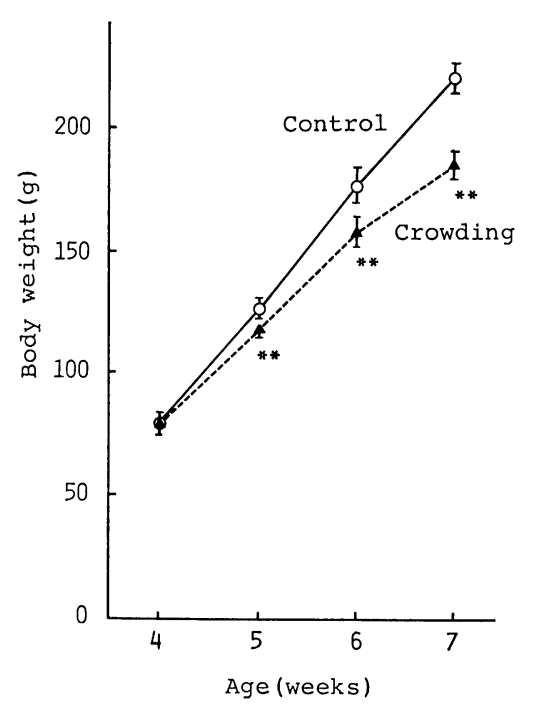

\begin{tabular}{cccc}
\hline Feed efficiency & & & \\
\hline Control & 0.44 & 0.39 & 0.35 \\
Crowding & 0.45 & 0.34 & 0.24 \\
\hline
\end{tabular}

Fig. 1. Body weight and feed efficiency of rats reared under severe crowding. Values represent the mean $\pm \mathrm{SD}$. Significant difference: $* * P<0.01$.

difference in body weight between both groups gradually became greater. The feed efficiencies of the severe-crowding-stress group were greatly diminished two and three weeks after the start of the experiment.

\section{EFFECTS OF CONTINUOUS HEAT $\left(31^{\circ} \mathrm{C}\right)$ ON THE INTESTINAL FLORA, GROWTH, AND FEED EFFICIENCY OF RATS}

A total of thirty 4-week-old male SD rats were divided into two groups. The heat stress and control groups were reared at $31^{\circ} \mathrm{C}$ and $25^{\circ} \mathrm{C}$, respectively, and at a relative humidity of $55 \%$ for three weeks. This experiment was carried out in an environment-control breeding apparatus (TUC-1 type, Tokiwa Co., Japan). All had ad libitum access to water and feed. The body-weight gains and feed efficiencies of each group were measured at regular intervals. At the end of the experiment, the intestinal flora in the ileum and feces of 6 rats in each group was examined.

Table 3 shows that the number of Enterobacteriaceae, Staphylococcus, and total aerobes significantly increased in the ileum while that of Spirochaetaceae was reduced in the feces. Figure 2 shows that the growth of the animals was significantly delayed one week after the start of the experiment and, as time passed, the difference in body weight between both groups became greater. The feed efficiency of the 
Table 3. Composition of intestinal flora of rats reared under continuous heat stress $\left(31^{\circ} \mathrm{C}\right)$

\begin{tabular}{|c|c|c|c|c|c|}
\hline \multirow{2}{*}{ Bacterial group } & \multicolumn{2}{|c|}{ Control } & \multicolumn{3}{|c|}{ Heating } \\
\hline & Ileum & Feces & Ileum & Feces & \\
\hline Enterobacteriaceae & $6.98 \pm 0.49^{a}(100)^{b}$ & $7.44 \pm 0.71(100)$ & $8.46 \pm 0.44^{d}(100)$ & $7.71 \pm 0.63$ & $(100)$ \\
\hline Pseudomonas & $(0)$ & $(0)$ & $(0)$ & & ( 0$)$ \\
\hline Streptococcus & $7.14 \pm 0.47$ & $8.31 \pm 0.81 \quad(100)$ & $7.11 \pm 0.42(100)$ & $8.33 \pm 0.69$ & (100) \\
\hline Staphylococcus & $4.61 \pm 0.34(100)$ & $5.89 \pm 0.68(100)$ & $6.62 \pm 0.93^{d}(100)$ & $6.10 \pm 0.39$ & (100) \\
\hline Corynebacterium & $(0)$ & $(0)$ & $5.30 \quad(25)$ & 6.18 & ( 14$)$ \\
\hline Bacillus & $(14)$ & $(14)$ & $(0)$ & 6.18 & ( 14$)$ \\
\hline Yeast & $(0)$ & $(0)$ & $(0)$ & & $(0)$ \\
\hline Mold & $(0)$ & $(0)$ & $(0)$ & & $(0)$ \\
\hline Total aerobes & $7.42 \pm 0.43$ & $8.40 \pm 0.78$ & $8.53 \pm 0.40^{d}$ & $8.36 \pm 0.54$ & \\
\hline Lactobacillus & $8.69 \pm 0.19(100)$ & $9.37 \pm 0.18(100)$ & $8.90 \pm 0.21(100)$ & $9.45 \pm 0.38$ & $(100)$ \\
\hline Bifidobacterium & $7.60 \pm 0.30(33)$ & $6.78 \pm 0.58(83)$ & $6.30 \quad(14)$ & $6.38 \pm 1.02$ & $(100)$ \\
\hline Eubacterium & $(0)$ & $9.23 \pm 0.08(33)$ & $(0)$ & $8.59 \pm 0.30$ & ( 50$)$ \\
\hline Bacteroidaceae & $7.20 \pm 0.49(83)$ & $9.93 \pm 0.19(100)$ & ( 14$)$ & $10.10 \pm 0.37$ & (100) \\
\hline Spirochaetaceae & $(0)$ & $9.27 \pm 0.29(50)$ & $(0)$ & $8.67 \pm 0.19^{c}$ & $(60)$ \\
\hline Clostridium & $7.30 \pm 0$ & $10.07 \pm 0.50(100)$ & ( 14$)$ & $10.18 \pm 0.39$ & (100) \\
\hline C. perfringens & $(0)$ & $(0)$ & $(0)$ & & $(0)$ \\
\hline Peptococcaceae & $(0)$ & $8.24 \pm 0.24(33)$ & $(14)$ & & $(0)$ \\
\hline Veillonellaceae & $(0)$ & $(0)$ & $(0)$ & & $(0)$ \\
\hline Total anaerobes & $8.66 \pm 0.28$ & $10.59 \pm 0.59$ & $8.98 \pm 0.31$ & $10.50 \pm 0.37$ & \\
\hline Total bacteria & $8.76 \pm 0.19$ & $10.60 \pm 0.59$ & $9.19 \pm 0.22^{d}$ & $10.51 \pm 0.37$ & \\
\hline
\end{tabular}

$a, b, c, d$ See the footnote to Table 1 .

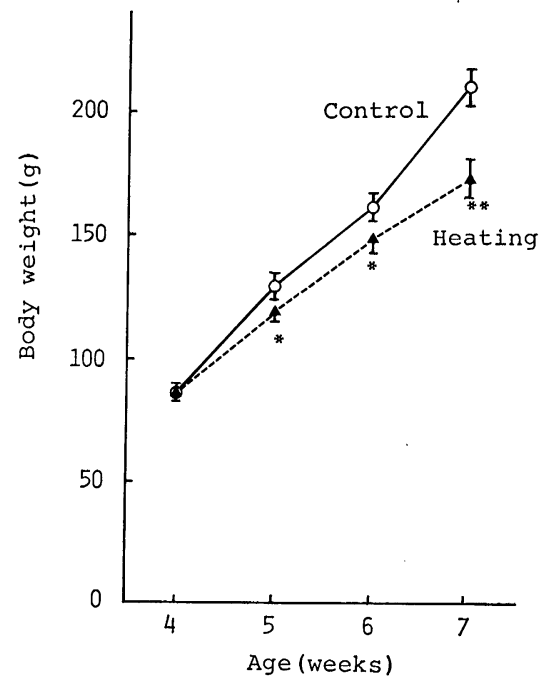

\begin{tabular}{llll}
\hline Feed efficiency & & & \\
\hline Control & 0.45 & 0.35 & 0.38 \\
Heating & 0.38 & 0.33 & 0.28 \\
\hline
\end{tabular}

Fig. 2. Body weight and feed efficiency of rats reared under continuous heating $\left(31^{\circ} \mathrm{C}\right)$. Values represent the mean $\pm \mathrm{SD}$. Significant difference: $* P<0.05, * * P<0.01$. 


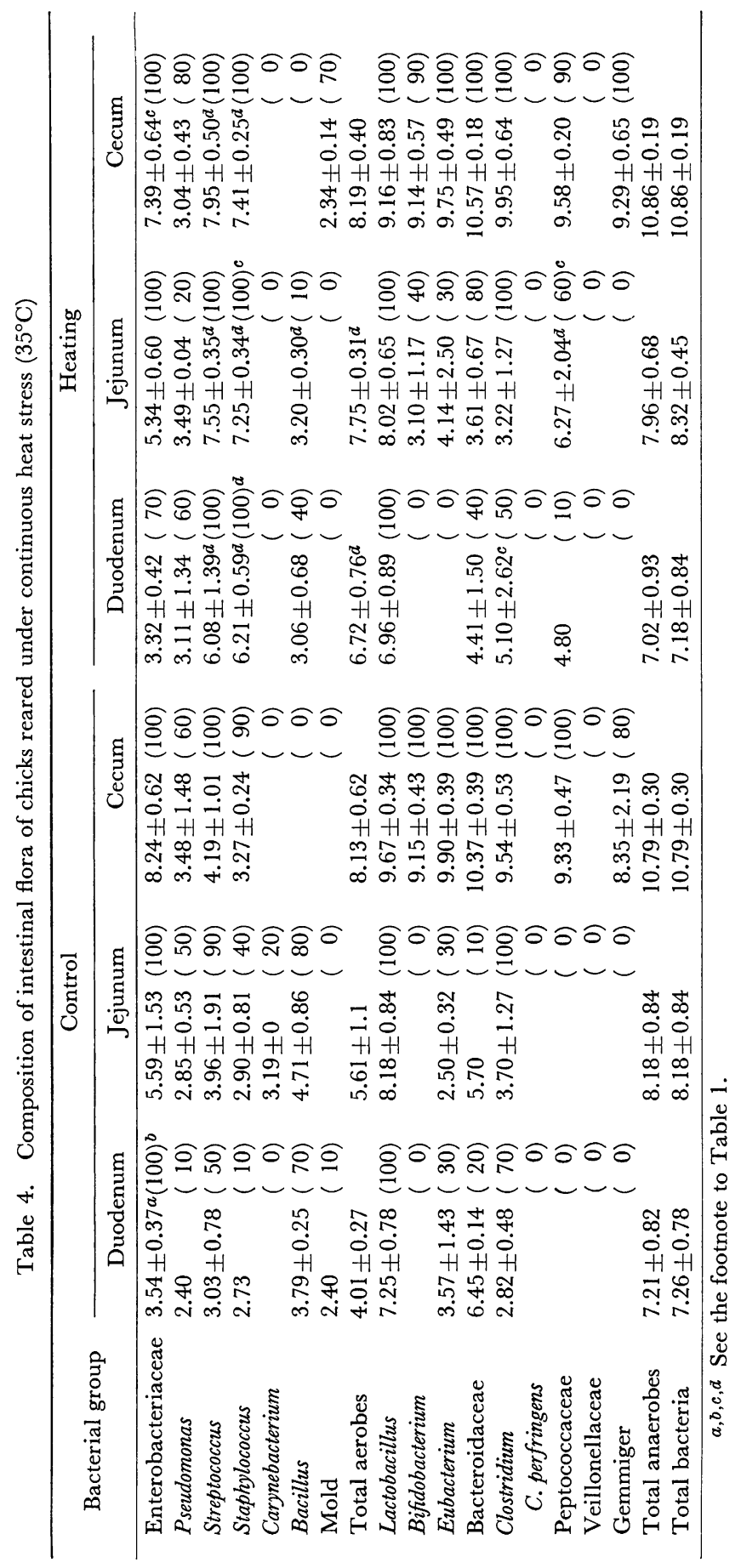


animals under heat stress was found to decrease throughout the experiment.

\section{EFFECTS OF CONTINUOUS HEAT $\left(35^{\circ} \mathrm{C}\right)$ ON THE INTESTINAL FLORA, GROWTH, AND FEED EFFICIENCY OF CHICKS}

Ninety White Leghorn chicks, 1-week-old males, were divided into two groups. The heat stress and control groups were reared at $35^{\circ} \mathrm{C}$ and $25^{\circ} \mathrm{C}$, respectively. Relative humidity was controlled at $55 \%$ in both groups. The breeding apparatus was the same as above mentioned. All animals were fed ad libitum an antibioticsfree standard diet (Clea Co. Japan) and water. Body-weight gain and feed efficiencies were computed weekly. All animals were killed after 4 weeks and the intestinal flora in the ileum and cecum of 10 chicks in each group was examined.

Table 4 shows the composition of the intestinal flora of the chicks reared under continuous heat stress $\left(35^{\circ} \mathrm{C}\right)$. In particular, the number of Streptococcus and Staphylococcus significantly increased in the entire intestine ranging from the duodenum to the cecum. The number of total aerobes in the duodenum and jejunem increased as well. The number of Clostridium and the number and detection rate of the Peptococcaceae increased in the duodenum and jejunum, respectively. Figure 3

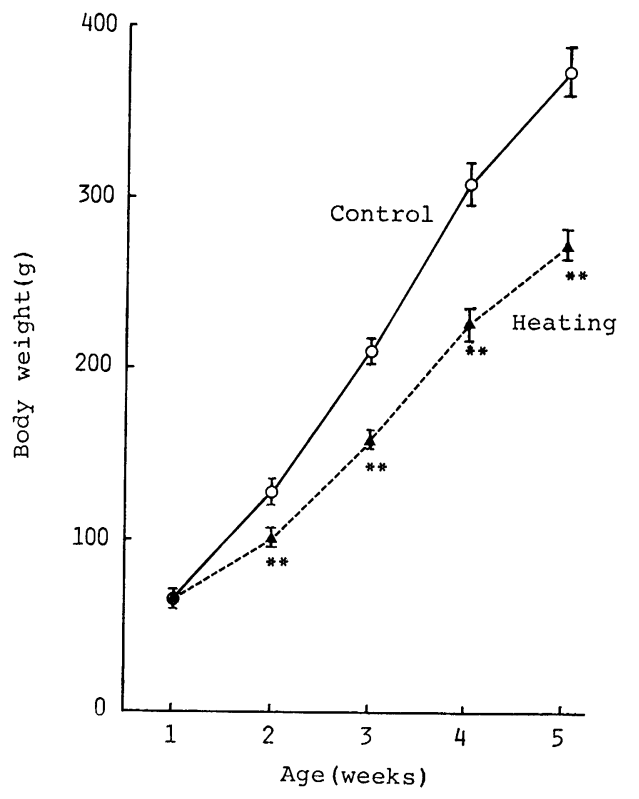

\begin{tabular}{llll}
\hline Feed efficiency & & & \\
\hline Control & 0.60 & 0.41 & 0.35 \\
Heating & 0.47 & 0.37 & 0.36 \\
\hline
\end{tabular}

Fig. 3. Body weight and feed efficiency of chicks reared under continuous heating $\left(35^{\circ} \mathrm{C}\right)$. Values represent the mean $\pm \mathrm{SD}$. Significant difference: $* * P<0.01$. 
shows that the growth of the heat stress group was significantly delayed even one week after the start of the experiment and, as time passed, the difference in body weight between both groups became greater. The feed efficiency of the heat stress group was greatly decreased one and two weeks after the start of the experiment.

\section{EFFECTS OF INTERMITTENT HEAT ON THE INTESTINAL FLORA, GROWTH, AND FEED EFFICIENCY OF CHICKS}

Ninety White Leghorn chicks, 2-week-old males, were divided into the following three groups: (1) intermittently reared at $20^{\circ} \mathrm{C}$ for three consecutive days and then at $33^{\circ} \mathrm{C}$ for two consecutive days; (2) intermittently reared at $20^{\circ} \mathrm{C}$ for three consecutive days and then at $38^{\circ} \mathrm{C}$ for two consecutive days; (3) intermittently reared at $20^{\circ} \mathrm{C}$ for five consecutive days and then at $42^{\circ} \mathrm{C}$ for two consecutive days.

The control groups were reared at $25^{\circ} \mathrm{C}$. The humidity was controlled at $55 \%$ in all groups. The body-weight gain of each animal was computed and the five kinds of bacteria (Enterobacteriaceae, Streptococcus, Staphylococcus, Lactobacillus, and Clostridium) in the duodenum, jejunum, ileum, and cecum of each animal were examined at intervals during the experiment. The other experimental conditions were the same as before.

In the $20-33^{\circ} \mathrm{C}$ heat stress group, the number of Staphylococcus in the jejunum increased after the animals were reared at $33^{\circ} \mathrm{C}$, although that of the other intestinal bacteria did not significantly increase. The intermittent heat $\left(33^{\circ} \mathrm{C}\right)$ did not affect the weight gain of the animals (Fig. 6A).

In the $20-38^{\circ} \mathrm{C}$ heat stress group, the numbers of Enterobacteriaceae, Staphylococcus, and Streptococcus in the duodenum, jejunum, and ileum were found to increase (Fig. 4). The weight gain was suppressed when the animals were reared at $38^{\circ} \mathrm{C}$ (Fig. 6A).

In the $20-42^{\circ} \mathrm{C}$ heat stress group, the number of Enterobacteriaceae, Staphylococcus, Streptococcus, and Clostridium in the entire intestine significantly increased after the animals were reared at $42^{\circ} \mathrm{C}$, while that of Lactobacillus in the cecum significantly decreased (Fig. 5). As shown in Fig. 6B, the weight gain of the animals was inhibited when they were subjected to heat $\left(42^{\circ} \mathrm{C}\right)$.

\section{EFFECTS OF THE ADMINISTRATION OF PROBIOTICS ON THE INTESTINAL FLORA, GROWTH, AND FEED EFFICIENCY OF THE CHICKS REARED UNDER HEAT STRESS}

The Lactobacillus acidophilus I-92 and L. salivarius I-130 (both originated from chickens) were orally administered to White Leghorn chicks, daily from the day of birth. These chicks suffered heat $\left(42^{\circ} \mathrm{C}\right)$ stress for two days when they were 9-10 days old and when they were 16-17 days old. The effects of the above administration on the body-weight gains of the animals were examined. The above 


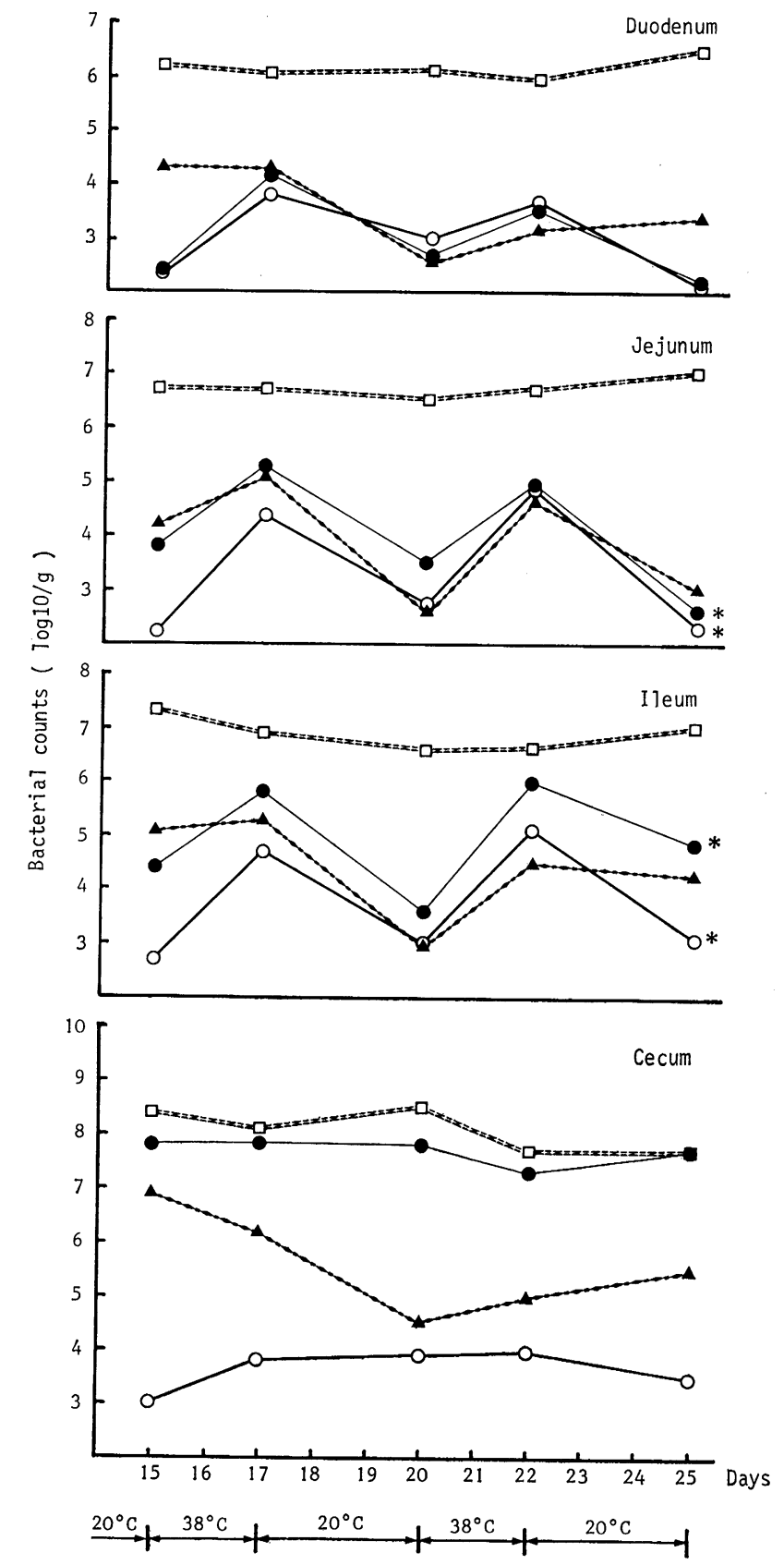

Fig. 4. Change in intestinal bacteria of chicks reared under an intermittent heating $\left(20-38^{\circ} \mathrm{C}\right)$. O, Enterobacteriaceae; O, Staphylococcus; $\Delta$, Streptococcus; $\Delta$, Clostridium; $\square$, Lactobacillus. Significant difference: $* P<0.05$. 

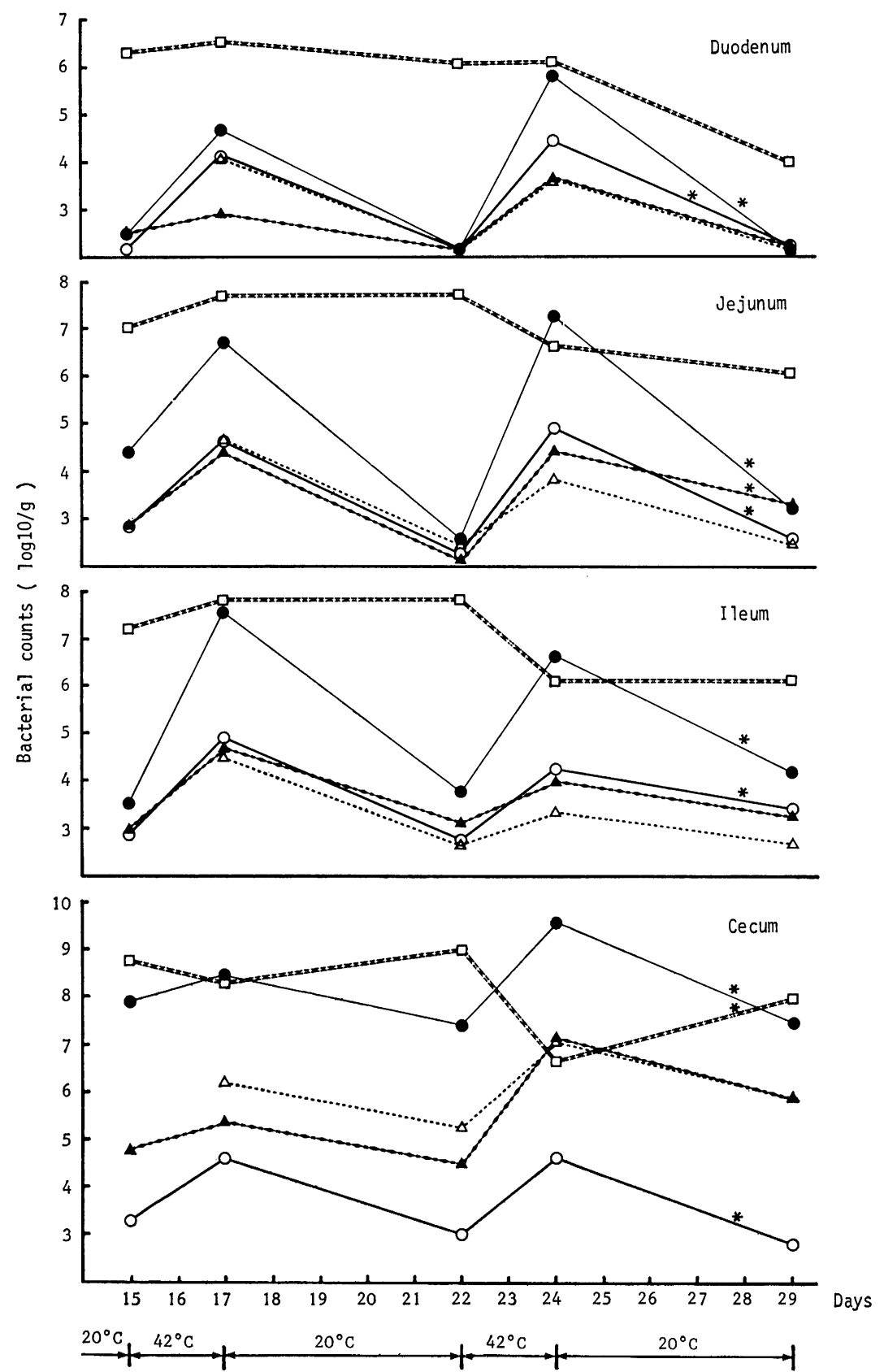

Fig. 5. Change in intestinal bacteria of chicks reared under an intermittent heating $\left(20-42^{\circ} \mathrm{C}\right)$. Symbols are the same as in Fig. 4. 

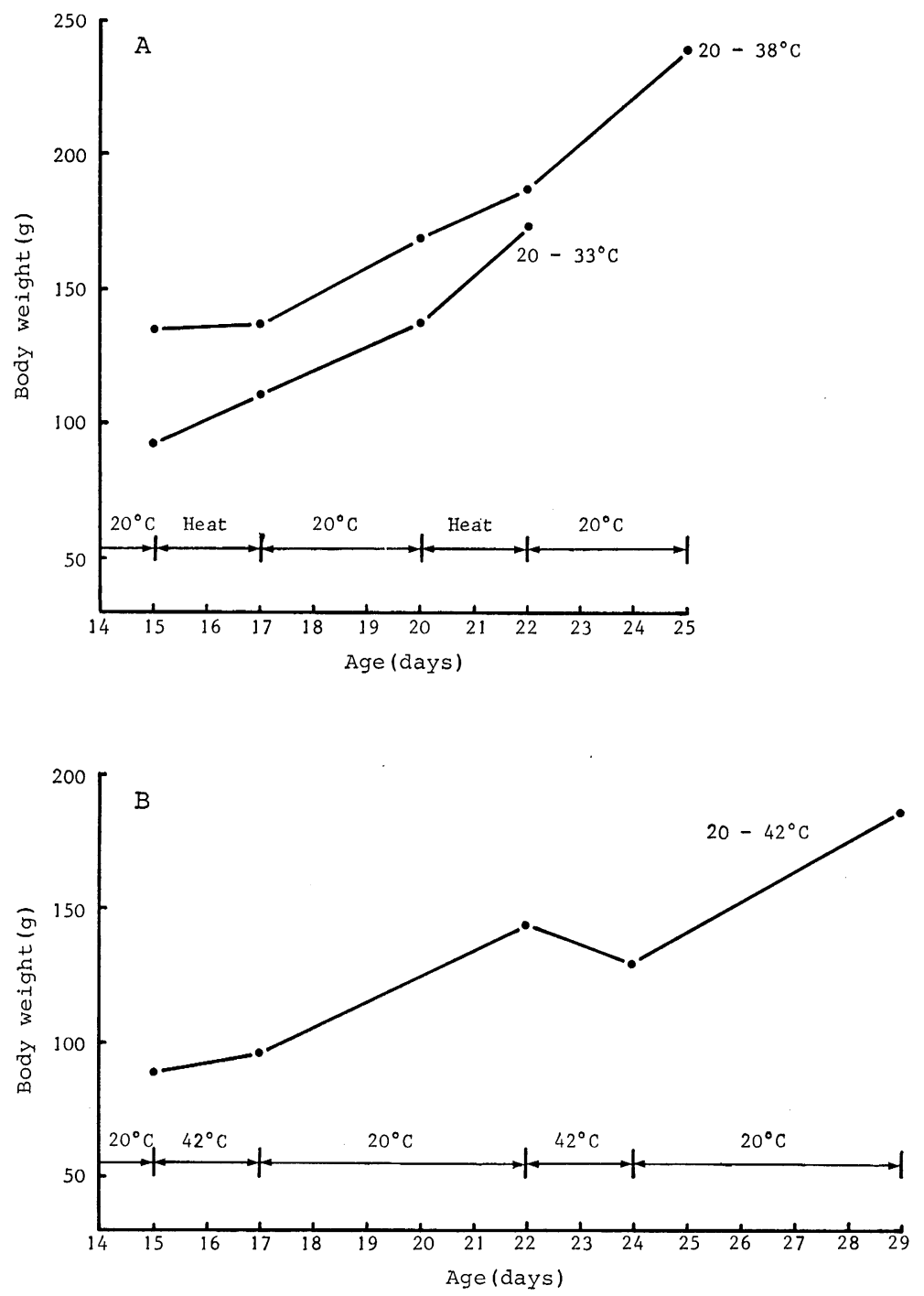

Fig. 6. Body weight of chicks reared under intermittent heating. A, 20-33 ${ }^{\circ} \mathrm{C}$ and $20-38^{\circ} \mathrm{C} ; \mathrm{B}, 20-42^{\circ} \mathrm{C}$.

Lactobacillus was cultured in the Brigg's broth for 18 hours and then the broth was centrifugally washed with phosphate-buffered saline. The above bacterial solution was adjusted to a concentration of $10^{9} / \mathrm{ml}$ before administration. The control group was administered phosphate-buffered saline only.

A mixture of Bifidobacterium pseudolongum $\mathrm{H}-15, \mathrm{H}-19$, and B. thermophilum T-111 (all originated from chickens) was administered to male White Leghorn chicks, daily from the day of birth. These chicks were forced to endure heat $\left(35^{\circ} \mathrm{C}\right)$ stress 


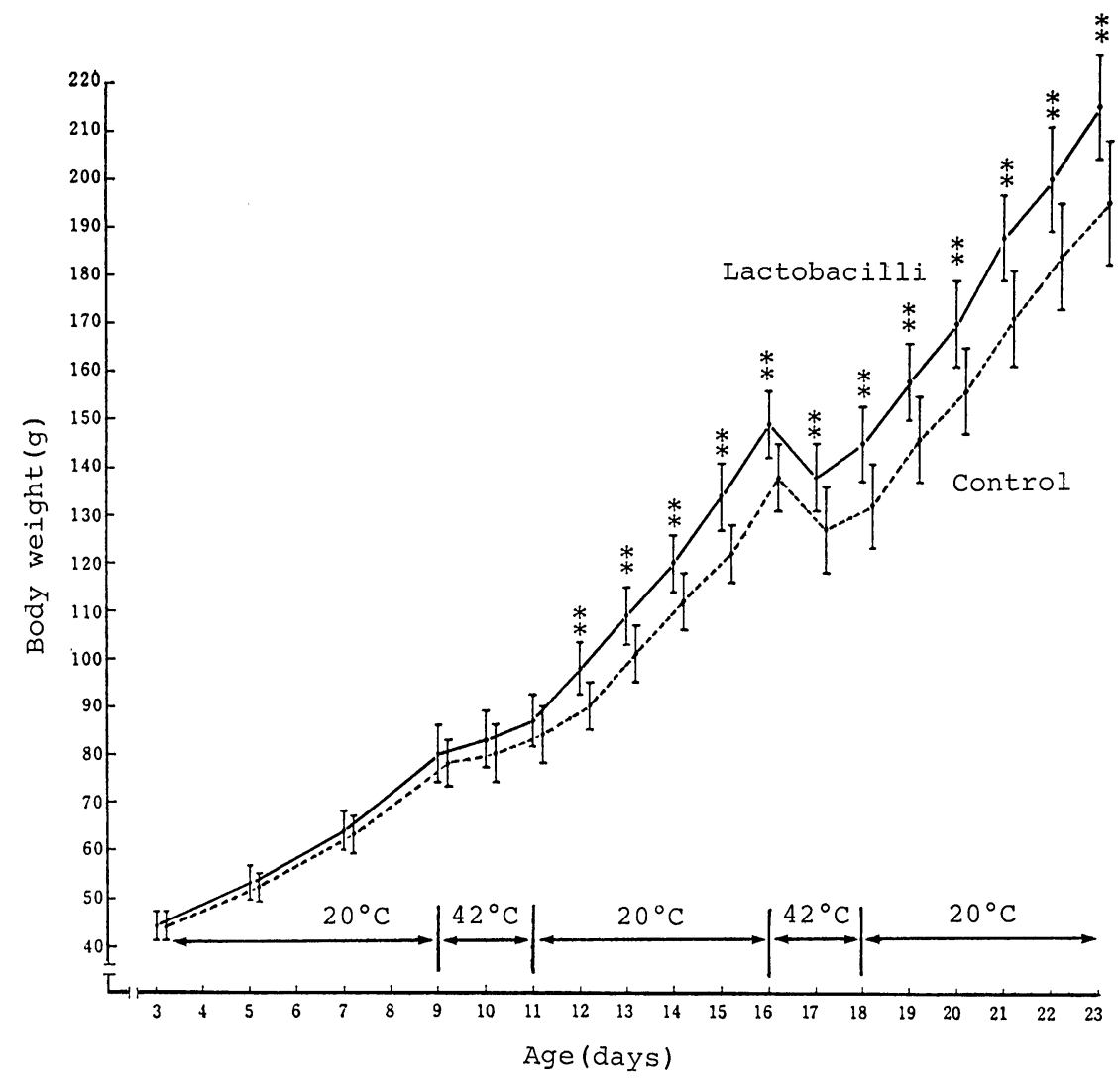

Fig. 7. Effect of the administration of lactobacilli on the growth of chicks reared under an intermittent heating $\left(20-42^{\circ} \mathrm{C}\right)$. Significant difference: $* * P<0.01$.

continuously after 9 days of age. The effects of the above administration on the intestinal flora, body-weight gains, and feed efficiencies of the animals were examined. The treated group was fed daily a diet containing the specified concentration of lyophilized Bifidobacterium, from which each animal received $10^{9}$ bacteria a day, from the day of birth. The control group was fed a diet containing only protective agents for lyophilized Bifidobacterium. The other experimental conditions were the same as above mentioned.

The animals of the Lactobacillus-treated group had already shown better growth than those of the control group even before both groups were subjected to intermittent heat. After the animals were 14 days old, the difference in body-weight between both groups became statistically significant. When the animals of both groups were subjected to intermittent heat $\left(42^{\circ} \mathrm{C}\right)$, their growth greatly declined. The Lactobacillus treatment relieved the intermittent heat stress, showing a significant weight gain compared to that of the control group (Fig. 7). 
Table 5. Feed efficiency of chicks administered bifidobacteria under continuous heat stress $\left(35^{\circ} \mathrm{C}\right)$

\begin{tabular}{lccccc}
\hline \multirow{2}{*}{ Group } & \multicolumn{5}{c}{ Weeks after administration } \\
\cline { 2 - 6 } & 1 & 2 & 3 & 4 & 5 \\
\hline Bifidobacteria & 0.56 & 0.53 & 0.35 & 0.42 & 0.50 \\
Control & 0.56 & 0.53 & 0.31 & 0.37 & 0.41 \\
\hline
\end{tabular}

Table 6. Composition of intestinal bacteria of chicks administered bifidobacteria under continuous heat stress $\left(35^{\circ} \mathrm{C}\right)$

\begin{tabular}{|c|c|c|c|c|}
\hline \multirow{2}{*}{ Bacterial group } & \multicolumn{2}{|c|}{ Control } & \multicolumn{2}{|c|}{ Bifidobacteria } \\
\hline & Jejunum & Cecum & Jejunum & Cecum \\
\hline Enterobacteriaceae & $7.3 \pm 0.6^{a}(100)^{b}$ & $8.0 \pm 0.4(100)$ & $6.3 \pm 0.8^{c}(100)$ & $7.9 \pm 0.3(100)$ \\
\hline Pseudomonas & $(0)$ & $3.1 \quad(20)$ & $2.8 \quad(20)$ & $(0)$ \\
\hline Streptococcus & $7.5 \pm 0.6(100)$ & $8.3 \pm 0.2(100)$ & $7.2 \pm 0.6(100)$ & $8.0 \pm 0.2(100)$ \\
\hline Staphylococcus & $5.6 \pm 0.6(100)$ & $5.0 \pm 0.8(100)$ & $4.8 \pm 0.8(100)$ & $5.2 \pm 1.7(100)$ \\
\hline Bacillus & $5.9 \pm 0.8(100)$ & - & $5.5 \pm 1.5(80)$ & - \\
\hline Corynebacterium & $7.3 \pm 0.5(100)$ & - & $5.4 \pm 0.8^{d}(100)$ & - \\
\hline Mold & $(0)$ & $(0)$ & $(0)$ & $(0)$ \\
\hline Total aerobes & $8.0 \pm 0.4$ & $8.5 \pm 0.3$ & $7.3 \pm 0.6$ & $8.5 \pm 0.5$ \\
\hline Lactobacillus & $8.5 \pm 0.4(100)$ & $9.2 \pm 0.4(100)$ & $8.4 \pm 0.6(100)$ & $9.5 \pm 0.4(100)$ \\
\hline Bifidobacterium & $(0)$ & $(0)$ & $7.0 \pm 0.5^{d}(100)^{c}$ & $9.1 \pm 0.5^{d}(100)^{c}$ \\
\hline Eubacterium & $5.7 \pm 0.5(100)$ & $9.5 \pm 0.6(100)$ & $5.4 \pm 1.1(100)$ & $8.7 \pm 0.5(100)$ \\
\hline Bacteroidaceae & $(0)$ & $9.8 \pm 0.3(100)$ & $6.8 \pm 1.3(40)$ & $10.2 \pm 0.2(100)$ \\
\hline Clostridium & $(0)$ & $10.1 \pm 0.1$ & $6.4 \pm 0.2(40)$ & $10.3 \pm 0.3(100)$ \\
\hline C. perfringens & $(0)$ & $(0)$ & $(0)$ & $(0)$ \\
\hline Peptococcaceae & $5.8 \pm 0.2(40)$ & $9.6 \pm 0.3(100)$ & $4.2 \pm 0.7(60)$ & $9.1 \pm 1.1(100)$ \\
\hline Gemmiger & $(0)$ & $9.6 \pm 0.5(80)$ & $(0)$ & $9.3 \pm 0.5(100)$ \\
\hline Veillonellaceae & $(0)$ & $(0)$ & $(0)$ & $(0)$ \\
\hline Total anaerobes & $8.5 \pm 0.4$ & $10.6 \pm 0.1$ & $8.5 \pm 0.5$ & $10.7 \pm 0.2$ \\
\hline Total bacteria & $8.7 \pm 0.3$ & $10.6 \pm 0.1$ & $8.5 \pm 0.5$ & $10.7 \pm 0.2$ \\
\hline
\end{tabular}

$a, b, c, d$ See the footnote to Table 1 .

-, not measured.

The effects of administration of Bifidobacterium on the growth of the animals under continuous heat $\left(35^{\circ} \mathrm{C}\right)$ stress were not statistically detected compared to the control group. The feed efficiency of the treated group, however, was significantly higher than that of the control group (Table 5). Examination of intestinal flora revealed that the number of Enterobacteriaceae, Streptococcus, Corynebacterium, and Peptococcaceae in the jejunum increased in the control group, while the growth of the above bacteria was inhibited in the Bifidobacterium-treated group. In particular, the number of Enterobacteriaceae and Corynebacterium was significantly reduced. Bifidobacterium was detected as a dominant bacterium in both the jejunum and cecum of the animals from the treated group, while this bacterium was not discovered at all in the animals from the control group (Table 6). 
Table 7. Summary of the influence of stresses on the intestinal flora of the host

\begin{tabular}{|c|c|c|c|c|}
\hline & \multicolumn{2}{|c|}{ Rat } & \multicolumn{2}{|c|}{ Chick } \\
\hline & Crowding & $\begin{array}{c}\text { Heating } \\
\left(31^{\circ} \mathrm{C}\right)\end{array}$ & $\begin{array}{c}\text { Heating } \\
\left(35^{\circ} \mathrm{C}\right)\end{array}$ & $\begin{array}{c}\text { Heating } \\
\left(20-42^{\circ} \mathrm{C}\right)\end{array}$ \\
\hline \multicolumn{5}{|l|}{ Intestinal flora } \\
\hline Staphylococcus & $\nearrow$ & $\nearrow$ & $\nearrow$ & $\nearrow$ \\
\hline Streptococcus & $\nearrow$ & - & $\nearrow$ & $\nearrow$ \\
\hline Enterobacteriaceac & 一 & $\nearrow$ & - & $\nearrow$ \\
\hline Corynebacterium & $\nearrow$ & - & - & - \\
\hline Clostridium & 一 & 一 & $\nearrow$ & $\nearrow$ \\
\hline Peptococcaceae & $\nearrow$ & - & $\pi$ & . \\
\hline Bacteroides & $\nearrow$ & - & - & - \\
\hline Lactobacillus & - & - & - & $\searrow$ \\
\hline Spirochaetaceae & - & $\searrow$ & - & $\cdot$ \\
\hline Total aerobes & $\nearrow$ & $\vec{\nearrow}$ & $\nearrow$ & - \\
\hline Total bacteria & 一 & $\nearrow$ & - & - \\
\hline Growth rate of host & $\searrow$ & $\searrow$ & $\searrow$ & $\searrow$ \\
\hline
\end{tabular}

\section{CONCLUDING REMARKS}

In these studies, the fact that the crowding and heat stress affect intestinal flora, body-weight gain, and feed efficiencies of the host was clarified. As summarized in Table 7, the change of intestinal flora caused by stress showed an almost common tendency, irrespective of the type of stress and host species. Aerobic bacteria, i.e., Staphylococcus, Streptococcus, Corynebacterium, and Enterobacteriaceae increased commonly in the small intestine. In regard to anaerobes, Peptococcaceae and Clostridium sometimes increased. The changes of bacterial flora in the large intestine showed the similar tendency as in the small intestine. In addition, Lactobacillus decreased under severe stress such as intermittent $20-42^{\circ} \mathrm{C}$ heat stress in the chicks.

The above results suggest that an animal under stress exhibits change in the normal composition of its intestinal flora in such a way that harmful bacteria increase in number but useful bacteria decline. Although there has been no investigation into change in the entire intestinal flora, it has been reported that the number of Escherichia coli, Streptococcus, and Clostridium perfringens increase while that of Lactobacillus declines in animals under conditions of crowding (Schaedler and Dubos (17), constraint (Tournut et al (22)), fasting (Smith (20); Tannok and Savage (21)), or other stress. The results of this study revealed that stress changed the number of all intestinal bacteria except $C$. perfringens and increased other bacteria. The above bacteria, multiplying quite rapidly in animals under stress, produce toxic substances in the intestine (Dang and Visek (3); Dubos et al $(5,6)$; Melnykowycz and Johansson (14)) and absorb nutrients (Anderson et al (1); Donaldson et al (4)), thus suppressing the growth of the host through its intestinal metabolism. The 
above phenomenon is assumed to reflect the host's biological response to stress. Reduction in the number of Lactobacillus, on the other hand, is thought to cause harmful bacteria to grow, inducing idiopathic infectious disease.

There may still exist unknown bacterial species, which change their number in the intestine of the animal under stress, other than those examined in this study. Holdeman et al (10) reported that human psychological stress such as fear increases the number of Bacteroides thetaiotaomicron (revised to $B$. uniformis thereafter). The relationship between stress and each bacterial species of intestinal flora needs to be further investigated in the future.

In these studies, administration of Lactobacillus or Bifidobacterium probiotics clearly improved suppression of growth or feed efficiency of the animal under stress. This might have resulted because the above administration may have improved unusual intestinal flora caused by stress, thus preventing harmful bacteria from absorbing nutrients and producing toxic substances, and increasing the immunological tolerance of the host. These actions are estimated to result in improvement in the growth and feed efficiency of the host. In the future, to ensure safe and effective rearing of livestock, administration of probiotics such as Lactobacillus may replace that of antibiotics that have been added to the diet.

\section{SUMMARY}

The effects of crowding and heat stress on the intestinal flora, body-weight gains, and feed efficiencies of rats and chickens as well as the effects of the administration of probiotics on the animals under stress were introduced. Irrespective of the type of stress and host species, the change of intestinal flora caused by stress showed almost the common tendency: when the animal suffered stress, Staphylococcus, Streptococcus, Corynebacterium, and Enterobacteriaceae commonly increased; when the stress was more severe, sometimes Peptococcaceae, Bacteroidaceae, and Clostridium also increased or Lactobacillus reduced. Body-weight gains and feed efficiencies were markedly suppressed under these stress conditions. Administering Lactobacillus to a chicken under heat stress improved its hypoplasia while administration of Bifidobacterium improved the feed efficiency and intestinal flora.

Acknowledgments. We thank R. Harasawa of the Department of Veterinary Microbiology, Faculty of Agriculture, Miyazaki University, and Y. Yoshitake of Toyo Jozo Co., Ltd., for cooperation with these investigations. We also thank A. Ozaki and T. Oowada of this Institute for their assistance in the care of the animals, and K. Sakamoto of Nippon Kayaku Co., Ltd., for his assistance in preparation of the manuscript. The supplying of Bifidobacterium probiotics from Dr. T. Kawashima, Morinaga Milk Industry Co., Ltd., is gratefully acknowleged.

These works were supported by research grants from the Science and Technology Agency of the Japanese Government.

\section{REFERENCES}

(1) Anderson, G.W., J.D. Cunningham, and S.J. Slinger. 1952. Effect of protein level and penicillin on growth and intestinal flora of chickens. J. Nutr. 47: 175-189. 
(2) Coates, M.E., C.D. Dickinson, G.F. Harrison, S.K. Kon, J.W.G. Porter, S.H. Cummins, and W.F.J. Cuthbertson. 1952. A mode of action of antibiotics in chick nutrition. J. Sci. Food Agric. 3: 43-48.

(3) Dang, H.C., and W.J. Visek. 1960. Effect of urease injection on body weights of growing rats and chicks. Proc. Soc. Exp. Biol. Med. 105: 164-167.

(4) Donaldson, R.M., Jr., H. Corrigan, and G. Natsios. 1962. Malabsorption of Co60-labeled cyanocobalamin in rats with intestinal diverticula. II. Studies on contents of diverticula. Gastroenterology 43: 282-290.

(5) Dubos, R.J., R. Costello, and R.M. Schaedler. 1965. The influence of endotoxin administration on the nutritional requirements of mice. J. Exp. Med. 122: 1003-1015.

(6) Dubos, R.J., and R.W. Schaedler. 1961. The effect of bacterial endotoxins on the water intake and body weight of mice. J. Exp. Med. 113: 921-934.

(7) Elam, J.F., R.L. Jacobs, J. Fowler, and J.R. Couch. 1954. Effect of dietary Clostridia upon growth-promoting responses of Penicillin. Proc. Soc. Exp. Biol. Med. 85: 645-648.

(8) Elam, J.F., R.L. Jacobs, W.L. Tidwell, L.L. Gee, and J.R. Couch. 1953. Possible mechanism involved in the growth-promoting responses obtained from antibiotics. J. Nutr. 49: 307-317.

(9) Forbes, M., and J.T. Park. 1959. Growth of germ-free and conventional chicks: effect of diet, dietary penicillin and bacterial environment. J. Nutr. 67: 69-84.

(10) Holdeman, L.V., I.J. Good, and W.E.C. Moore. 1976. Human fecal flora: variation in bacterial composition within individuals and a possible effect of emotional stress. Appl. Environ. Microbiol. 31 : 359-375.

(11) Huhtanen, C.N., and J.M. Pensack. 1965. The role of Streptococcus faecalis in the antibiotic growth effect in chickens. Poult. Sci. 44: 830-834.

(12) Ito, S. 1981. "Hormone," Science (Extra number), p. 204-217, Nippon Keizai Shimbun Sha, Tokyo.

(13) Ito, S., and M. Kawakami. 1979. "Tekiou To Nou-Horumon" (Adaptation and Brain Hormone), Rikogakusha, Tokyo.

(14) Melnykowycz, J., and K.R. Johansson. 1955. Formation of amines by intestinal microorganisms and the influence of chlortetracycline. J. Exp. Med. 101: 507-517.

(15) Mitsuoka, T. 1980. "Chounaikin No Sekai-Kenkiseikin No Bunri To Doutei”' (A color Atlas of Anaerobic Bacteria: Isolating and Identifying the Anaerobes), Soubun Sha, Tokyo.

(16) Mitsuoka, T., K. Ohno, T. Benno, K. Suzuki, and K. Namba. 1976. The fecal flora of man. IV. Communication: comparison of the newly developed method with the old conventional method for the analysis of intestinal flora. Zentralbl. Bakteriol. Parasitenkd. Infektionskr. Hyg. Abt. I. Orig. A234: 219-233.

(17) Schaedler, R.W., and R.J. Dubos. 1962. The fecal flora of various strains of mice. Its bearing on their susceptibility to endotoxin. J. Exp. Med. 115: 1149-1160.

(18) Selye, H. 1936. Thymus and adrenals in the response of the organism to injuries and intoxications. Br. J. Exp. Pathol. 17: 234-248.

(19) Sieburth, J.M., J. Gutierrez, J. McGinnis, J.R. Stern, and B.H. Schneider. 1951. Effect of antibiotics on intestinal microflora and on growth of turkeys and pigs. Proc. Soc. Exp. Biol. Med. 76: 15-18.

(20) Smith, H.W. 1962. The development of the bacterial flora of the faeces of animals and man: the changes that occur during ageing. J. Appl. Bacteriol. 24: 235-241.

(21) Tannok, G.W., and D.C. Savage. 1974. Influences of dietary and environmental stress on microbiol populations in the murine gastrointestinal tract. Infect. Immun. 9: 591-598.

(22) Tournut, J., C. Labie, P. Redon, O. Sarraut, and J. Badia. 1969. La flora intestinale du porc en contrainte. Cah. Med. Vet. 38: 181-190. 